\title{
Activation of Biomass-Derived Charcoal Sorbents and Its Effect on Metal Sorption
}

AMY LAM ${ }^{1}$, JAELA BECK-LAMBERT ${ }^{1}$, TODD L. LONGBOTTOM $^{2}$, NELLI K. BODIFORD ${ }^{3}$, OMAR HARVEY ${ }^{2}$

${ }^{1}$ Department of Environmental Sciences, Texas Christian University, Fort Worth, TX 76129, USA

(amy.lam@tcu.edu)

${ }^{2}$ Department of Geological Sciences, Texas Christian University, Texas 76129, USA (omar.harvey@tcu.edu)

${ }^{3}$ Department of Chemistry and Biochemistry, Texas Christian University, Fort Worth, TX, USA (n.bodiford@tcu.edu)

Acid activation is known to alter the variability of surface properties found on pyrogenic organic matter ${ }^{1}$. However, it has mostly been described qualitatively. This poster presentation will quantitatively explore these properties and its link to heavy metal sorption. Specifically, this presentation will compare the surface heterogeneity $\left(\phi_{\text {surf }}\right)^{2}$ and adsorption kinetics of $\mathrm{Pb}^{2+}$ of activated charcoal sorbents to those of unactivated charcoal sorbents.

Results from $\mathrm{Pb}^{2+}$ sorption shows that when activated and heat-treated at $650^{\circ} \mathrm{C}$, charcoal sorbents adsorbed about $85 \%$ more than unactivated charcoal sorbents. This indicates the possibility of either more pore sites or surface functional groups available to adsorbed lead. This presentation will further discuss these results, methodology, and modeling applications.

(1) Güzel, Saygili, Saygili, Koyuncu, Yilmaz (2017), Journal of Cleaner Production 144 260-265.

(2) Harvey, Leonce \& Herbert (2018), Environmental Science \& Technology 52(11), 6167-6176. 